\title{
Sequential blood lactate measurement as a predictor of mortality in patients with sepsis in the critical care unit
}

\section{Pollov Borah}

Jorhat Medical College and Hospital

\section{Dilip Kumar Saloi}

Jorhat Medical College and Hospital

\section{Bipul Deka}

Jorhat Medical College and Hospital

\section{Ranjumoni Konwar}

FAAMC and Hospital https://orcid.org/0000-0003-1101-5067

\section{Deepjyoti Kalita}

All India Institute of Medical Sciences, Rishikesh

Putul Mahanta ( $\sim$ drpmahanta@gmail.com)

Assam Medical College and Hospital https://orcid.org/0000-0002-2716-4879

\section{Sangeeta Deka}

All India Institute of Medical Sciences, Rishikesh

\section{Chiranjita Phukan}

Tezpur Medical College and Hospital

\section{Research}

Keywords: Blood lactate levels, SIRS, intensive care unit (ICU), survivors, non-survivors

Posted Date: January 13th, 2021

DOl: https://doi.org/10.21203/rs.3.rs-143668/v1

License: (1) (1) This work is licensed under a Creative Commons Attribution 4.0 International License. Read Full License 


\section{Abstract}

Background and objective

In severe sepsis, increased blood lactate levels are observed indicating impaired oxidative phosphorylation, which secondarily causes hypoxic hypoxia and stagnant tissue hypoxia. Among all other related factors, a high rise of the lactate level in blood may be a useful predictor of sepsis patients' mortality. This study aims to determine the association of consecutive blood lactate levels with the patient's mortality with sepsis admitted in the Critical Care Unit (CCU).

Methods

This prospective study included 50 patient of septicemia at CCU above 18 years in a tertiary care centre. On admission, at 24 hours and 72 hours, blood lactate levels were monitored. Their clinical status was evaluated for 28 days to categorise as survivor and non-survivor. The statistical analysis was made with Microsoft Excel and SPSS version 20. To test the difference in mean blood lactate levels among survivors and non-survivors Student's t-test was applied. A p-value of less than 0.05 was considered significant. Prior ethical clearance from the institutional ethics committee of human with informed consent from the patients was obtained for data collection.

Results

The current study included 50 patients of septicemia, 23 were survivors, and 27 were non-survivors after 28 days of follow up. The mean lactate range for the 23 survivors was ranged from $0.43 \mathrm{mmol} / \mathrm{l}$ to 5.69 $\mathrm{mmol} / \mathrm{l}$, whereas for non-survivors, it was $1.64 \mathrm{mmol} / \mathrm{l}$ to $6.14 \mathrm{mmol} / \mathrm{l}$. The mean value of lactate for the survivors and non-survivors during admission, at 24 hours and at 72 hours were $0.9545 \pm 0.45798$ vs $2.5204 \pm 1.51498,1.2461 \pm 1.21360$ vs $2.5107 \pm 1.63678$ and $1.5496 \pm 1.66788$ vs $2.7904 \pm 2.00160$. The differences between the mean lactate values between survivors and non-survivors at different time intervals were highly significant.

Conclusion

A slower rate of lactate clearance during hospitalisation may be a significant factor associated with severe sepsis patient mortality. Thus serial blood lactate levels is a significant predictor of mortality and should be monitored.

\section{Introduction}

Sepsis is defined as a systemic inflammatory response syndrome (SIRS) secondary to a suspected infection. ${ }^{1}$ SIRS may is defined with the presence of two or more of the criteria, viz., body temperature > $38^{0} \mathrm{C}$ or $<36^{0} \mathrm{C}$, heart rate $>90$ beats/minute, a respiratory rate $>20 /$ minute or partial arterial pressure of 
carbon dioxide $(\mathrm{PCO} 2)<32 \mathrm{mmHg}$, white blood count $(\mathrm{WBC})>12,000 / \mathrm{mm}^{3}$ or $<4,000 / \mathrm{mm}^{3}$, or the presence of $>10 \%$ immature neutrophils (band forms). ${ }^{2}$

Many variables measured in critically ill patients have been used to estimate the severity of the disease, predict morbidity and mortality, evaluate costs of treatment, and finally, indicate specific treatment and monitor the adequacy of treatment and its timing. It is unlikely that one measurement can replace all of these, but lactate levels may come close in this manuscript's remainder. ${ }^{3}$

Increased blood lactate levels in severe sepsis and septic shock commonly indicate impaired oxidative phosphorylation, secondary to decreased oxygen availability to the cells (hypoxic hypoxia), and tissue hypoperfusion (stagnant hypoxia). ${ }^{4}$ In the ICU, blood lactate monitoring is widely used as an indirect marker of tissue hypoxia. ${ }^{5,6}$ Current guidelines for severe sepsis and septic shock resuscitation recommend that patients with severe sepsis or septic shock with an initial blood lactate level twice above the standard limit (4 mmol/l) should be promptly resuscitated. ${ }^{1}$ Studies had shown that lactate prognostic potential for mortality and other outcomes are ubiquitous and primarily focus on the early stage of sepsis management, which can be defined as the initial 6 hours and is widely referred to as the 'golden hours.' Blood lactate concentration is a parameter commonly used in intensive care units to assess tissue oxygenation with severe hyperlactatemia during shock is a standard indicator of cellular hypoxia. ${ }^{8}$

Therefore, the current study aims to examine whether blood lactate levels are a predictor in real sense for hospital mortality in patients with sepsis admitted in CCU.

\section{Materials And Methods}

This hospital-based observational study was conducted in the Department of Anesthesiology admitted in the ICU. A total of 50 patients above 18 years were studied after the approval from the Institutional Ethics Committee of the institute and with due informed consent.

Lactate blood level at regular intervals, i.e., on admission, 24 hours, 72 hours were monitored and recorded. Data thus collected were presented as frequency, percentage and mean and in \pm standard deviation. The patients were followed up for 28 days and categorised as survivor or non-survivor depending upon the outcome status. The statistical analysis was done using the Microsoft Excel and Statistical package for social sciences for windows version 22. The differences in mean blood lactate levels were tested using t-test. The $p$-value of less than 0.05 was considered significant.

\section{Results}

\section{Details of study participants:}


Among the 50 participants, 29 (58\%) were male, and 21 (42\%) were females. Majority of the patients (38.0\%) belonged to the higher age group of $46-60$ years, followed by patients of age group 30-45 years (30.0\%). The mean age ( \pm standard deviation) of the study participants was $45.06( \pm 3.26)$ years, as shown in Table 1.

Table 1 Details of the study participants

\begin{tabular}{|lll|}
\hline Age group & Frequency & Percentage \\
\hline$<30$ years & 8 & 16.0 \\
\hline $30-45$ years & 15 & 30.0 \\
\hline $46-60$ years & 19 & 38.0 \\
\hline$>60$ years & 8 & 16.0 \\
\hline Sex & & \\
\hline Male & 29 & 58.0 \\
\hline Female & 21 & 42.0 \\
\hline
\end{tabular}

Among the 50 patients included in the study, 23 were survivors, and 27 were non-survivors during 28 days follow up. The mean $( \pm)$ age of non-survivors was 44.35 ( \pm 11.64 ) years, and in survivors, it was 36.60 ( \pm 9.28) years. This reveals that the non-survivors were from the high age group compared to the survivors, as shown in Table 1.

\section{Distribution of lactate value among survivors and non-survivors:}

The mean lactate value ranged from $0.43 \mathrm{mmol} / \mathrm{l}$ to $5.69 \mathrm{mmol} / \mathrm{l}$ among survivors. Majority of the survived patients $(69 \%)$ had a lower lactate value of $0-2 \mathrm{mmol} / \mathrm{l}$. While the mean lactate range amongst the non-survivor was found to be between $1.64 \mathrm{mmol} / \mathrm{l}$ to $6.14 \mathrm{mmol} / \mathrm{l}$. Majority of the non-survivors had a higher lactate value of $>2 \mathrm{mmol} / \mathrm{l}$, as shown in Table 2 .

Table 2 Number of survivors and non-survivors at different lactate range 


\begin{tabular}{|lllll|}
\hline \multicolumn{3}{|c}{ Survivor } & \multicolumn{3}{c|}{ Non- survivor } \\
\hline $\begin{array}{l}\text { Lactate Value } \\
(m m o l / l)\end{array}$ & $\begin{array}{l}\text { Number } \\
(\boldsymbol{n})\end{array}$ & $\begin{array}{l}\text { Percentage } \\
(\%)\end{array}$ & Number(n) & Percentage (\%) \\
\hline $0-2$ & 16 & 69.00 & 13 & 48.00 \\
\hline $2.1-4$ & 4 & 17.00 & 8 & 29.00 \\
$>4$ & 3 & 14.00 & 6 & 23.00 \\
\hline Total & 23 & 100.00 & 27 & 100.00 \\
\hline
\end{tabular}

Serial lactate levels among patients at different time intervals:

Table 3 represents the change in patients, both survivors and non-survivors, at different lactate range in the various time intervals. The gradual decrease in the number of patients with lactate range $0-2 \mathrm{mmol} / \mathrm{l}$ was observed during the 72 hours from 26 patients at the time of admission to 20 patients at 72 hours. Simultaneously, an elevation in the number of patients with lactate $\geq 2 \mathrm{mmol} / \mathrm{l}$ was observed with increasing time. Patients with $>4 \mathrm{mmol} / \mathrm{l}$ lactate value increased significantly from 4 numbers at the time of admission to 10 numbers at 24 hours and up to 18 numbers at 72 hours. A significant ( $p$-value $=$ 0.016) association was observed among the patient's number, various time intervals, and different lactate levels.

Table 3 Patients, both survivors and non-survivors, at different lactate range in the different intervals

\begin{tabular}{|lllll|}
\hline $\begin{array}{l}\text { Lactate value } \\
(\mathrm{mmol} / \mathrm{l})\end{array}$ & On admission & At 24 hours & At 72 hours & $p$-value \\
\cline { 1 - 2 } & 26 & 22 & 20 & 0.016 \\
\hline $2.1-4$ & 20 & 18 & 12 & \\
\cline { 1 - 3 }$>4$ & 4 & 10 & 18 & \\
\hline
\end{tabular}

\section{Mean lactate levels at different time intervals among survivors and non-survivors:}

The mean lactate value at the time of admission was found significantly higher ( $\mathrm{p}$-value $<0.001$ ) among non-survivors as compared to that of survivors (2.5204 \pm 1.51498 vs $0.9545 \pm 0.45798)$. Similarly, the mean lactate values were higher among non-survivors at 24 hours $(2.5107 \pm 1.63678)$ and at 72 hours

$(2.7904 \pm 2.00160)$ than those of the survivors $(1.2461 \pm 1.21360$ at 24 hours and $1.5496 \pm 1.66788$ at 72 hours) and the variance was significant ( $p$ value $<0.05$ ), as shown in Table 4.

Table 4 Mean Lactate value among survivors and non-survivors 


\begin{tabular}{|c|c|c|c|c|}
\hline Lactate & Outcome & $\begin{array}{l}\text { Number } \\
\text { (n) }\end{array}$ & $\begin{array}{l}\text { Mean } \pm S D \\
(m m o l s / l)\end{array}$ & $p$-value \\
\hline \multirow[t]{2}{*}{ Admission } & Not Survived & 27 & $2.5204 \pm 1.51498$ & \multirow[t]{2}{*}{0.000} \\
\hline & Survived & 23 & $0.9545 \pm 0.45798$ & \\
\hline \multirow[t]{2}{*}{24 hours } & Not Survived & 27 & $2.5107 \pm 1.63678$ & \multirow[t]{2}{*}{0.004} \\
\hline & Survived & 23 & $1.2461 \pm 1.21360$ & \\
\hline \multirow[t]{2}{*}{72 hours } & Not Survived & 27 & $2.7904 \pm 2.00160$ & \multirow[t]{2}{*}{0.023} \\
\hline & Survived & 23 & $1.5496 \pm 1.66788$ & \\
\hline
\end{tabular}

\section{Discussion}

An association of amplified blood lactate levels with tissue hypoxia established in the current study agrees with Krishna $\mathrm{U}$ et al., ${ }^{9}$ where they found a relationship with over the circulatory failure patients.

An increased lactate level in the patient with sepsis reflects a marker of hypoxia, which agrees with a review of Krishna $\mathrm{U}$ et al., where they had compared the mean lactate values in patients with sepsis survivor non-survivor lactate value in $\mathrm{mg} / \mathrm{dl}^{9}{ }^{9}$

The patient who survived has a lower mean lactate value, which reaches normal in 36 hours. Still, the non-survivors showed persistent higher mean lactate value in the current study agrees on a review. ${ }^{10}$

A study conducted by Nguyen HB et al., ${ }^{11}$ reported a significant relationship ( $p$-value $\left.<0.005\right)$ between survivors and non-survivors with lactate clearance between the two groups agree on the current outcomes. They concluded that lactate clearance had a significant inverse relationship with mortality. This study matched the results with our research, where we noticed that mean arterial blood lactate range among that non-survivors were increasing at the given intervals of time. The study performed by Blum A et al., ${ }^{12}$ found that non-survivors groups had significantly higher lactate levels than in the survivors' groups. ${ }^{12}$ The results of this study was in favour of our research.

In a study conducted by Sanderson $\mathrm{M}$ et al. ${ }^{13}$, the findings revealed a linear relationship between increased lactate and increased mortality. This was following our study, where increased arterial blood lactate was significantly linked with high death incidences. Our study had a similar agreement with the research done by Yong Joo Park et al., ${ }^{14}$ where the patient group with more lactate level showed higher mortality than the group with the lower lactate level.

Our observations were also consistent with results obtained in another similar study conducted by Bou $\mathrm{R}$ et al. ${ }^{15}$ The said review reported $12 \%$ mortality with the lactate level of $2-4 \mathrm{mmol} / \mathrm{l}$ and higher mortality of $40.7 \%$ with lactate level $>4 \mathrm{mmol} / \mathrm{l}$. In distinction, another review ${ }^{16}$ reported insignificant differences of 
lactate during the initial period between the two groups. However, the decrease in blood lactate levels in the first 24 hours was more significant in the survivor than in the non-survivor, the results of the study matched with the results of our research.

\section{Conclusion}

The current study showed an increase in the number of patients with higher lactate levels at different time intervals, particularly in the non-survivors groups. Significantly the mean lactate levels were substantially higher midst non-survivors than survivors throughout the additional time intervals, indicating a significant association between high lactate levels resulting from low lactate clearance in the course of treatment and patient mortality with septicaemia. Thus, we can conclude that serial blood lactate levels may be a potential factor in predicting sepsis patients' mortality.

\section{Declarations}

Declaration: We all the authors have declared that all together with design, conceived this study, wrote this manuscript, revised it, and approved for publication. We also report that the manuscript's content has not been published, or submitted for publication elsewhere.

Ethical Approval and Consent to participate: Before collecting the data, ethical approval was obtained from the 'Institutional Ethics Committee' of Assam Medical College and Hospital, Assam, India. Also, informed consent was taken before the examination and collection of the data.

Consent for publication: Taken.

Availability of supporting data: All the data included in the manuscript.

Competing interests: None declared.

Funding: None declared.

Authors' contributions:

Acknowledgements: We are wholeheartedly grateful to our patients who have given their consent to participate in this study.

\section{References}

1. Dellinger RP, Levy MM, Rhodes Andrew, Annane Djillali, Gerlach Herwig, Steven M Opal MS, et al. Surviving sepsis campaign: international guidelines for management of severe sepsis and septic shock: 2012. Crit Care Med 2013 Feb;41(2):580-637. doi: 10.1097/CCM.0b013e31827e83af.

2. Bone RC, Balk RA. Definitions for sepsis and organ failure and guidelines for the use of innovative therapies in sepsis. Crit Care Med 1992;101(6):1644-55. 
3. Bakker J, Nijsten NM and Jansen CT. Clinical use of lactate monitoring in critically ill patients. Annals of Intensive Care 2013;3:12. doi: 10.1186/2110-5820-3-12.

4. Garcia-Alvarez M, Marik P, Bellomo R. Sepsis-associated hyperlactatemia. Crit Care 2014 Sep 9;18(5):503. doi: 10.1186/s13054-014-0503-3.

5. Jansen TC, Van BJ, Bakker J. Blood lactate monitoring in critically ill patients: a systematic health technology assessment. Crit Care Med 2009;37(10):2827-39.

6. Nathan I Shapiro, Michael D Howell, Daniel Talmor, Larry A Nathanson, Alan Lisbon, Richard E Wolfe, et al. Serum Lactate as a predictor of mortality in emergency department patients with infection. Ann Emerg Med 2005 May;45(5):524-8. doi: 10.1016/j.annemergmed.2004.12.006.

7. Chertoff J, Chisum M, Garcia B and Lascano J. Lactate kinetics in sepsis and septic shock: a review of the literature and rationale for further research. J Intensive Care 2015 Oct 6;3:39. doi:

10.1186/s40560-015-0105-4.

8. Levraut A, Ciebiera PJ, Chave S, Rabary O, Jambou P, Carles M et al. Mild hyperlactatemia in stable septic patients is due to impaired lactate clearance rather than overproduction. Am J Respir Crit Care Med 1998;157:1021-1026.

9. Krishna U, Joshi PS, Modh M. An evaluation of serial blood lactate measurement as an early predictor of shock and its outcome in patients of trauma or sepsis. Indian J Crit Care Med April-June 2009;13(2):66-73. doi: 10.4103/0972-5229.56051

10. Megrelli A, Oliveria P. R and Friedman G. Occult hypoperfusion is associated with increased mortality in hemodynamically stable, high-risk, surgical patients. Crit Care 2004 Apr;8(2):R60-5. doi: $10.1186 / \mathrm{cc} 2423$.

11. Nguyen HB, Rivers EP, Knoblich BP, Jacobsen G, Muzzin A, Ressler JA et al. Early lactate clearance is associated with improved outcome in severe sepsis and septic shock. Crit Care Med 2004 Aug;32(8):1637-42. doi: 10.1097/01.ccm.0000132904.35713.a7.

12. Blum A, Zoubi A.A, Nava K.S. High serum lactate level may predict death within 24 hours 2015 June 11;10(1):318-322. doi: 10.1515/med-2015-0045.

13. Miriam Sanderson, Marc Chikhani, Esme Blyth, Sally Wood, lain K Moppett, Tricia McKeever, et al. Predicting 30-day in patients with sepsis: An exploratory analysis of process of care and patient characteristics. J Intensive Care Soc 2018 Nov;19(4):299-304. doi: 10.1177/1751143718758975.

14. Yong Joo Park, Dong Hoon Kim, Seong Chun Kim, Tae Yun Kim, Changwoo Kang, Soo Hoon Lee, et al. Serum lactate upon emergency department arrival as a predictor of 30-day in-hospital mortality in an unselected population. PLoS One 2018 Jan 2;13(1):e0190519. doi: 10.1371/journal.pone.0190519.

15. Bou R, Christopher EK, Shamil A, Eva R, Faris M, Bachir R et al. Serum lactate is an independent predictor of hospital mortality in critically ill patients in the emergency department: a retrospective study. Scand J Trauma Resusc Emerg Med 2017 Jul 14;25(1):69. doi: 10.1186/s13049-017-0415-8.

16. J Bakker, P Gris, M Coffernils, R J Kahn, J L Vincent. Serial blood lactate levels can predict the development of multiple organ failure following septic shock. Am J Surg 1996 Feb;171(2):221-6. 
doi: 10.1016/S0002-9610(97)89552-9. 